\title{
Distribución de plantas hospedantes silvestres de Xylella fastidiosa subsp. fastidiosa en México
}

\section{Distribution of wild host plants of Xylella fastidiosa subsp. fastidiosa in Mexico}

\section{Acta Botanica Mexicana}

\author{
María Margarita Oliva-Hurtado1,4 (D), Daniel Téliz-Ortiz' (D), Laura Delia Ortega-Arenas² (D), Andrés Quezada-Salinas³ (iD
}

\section{Resumen:}

Antecedentes y Objetivos: Xylella fastidiosa subsp. fastidiosa, agente causal de la enfermedad de Pierce, es una $\gamma$-proteobacteria nativa de América y presente en México en zonas vitivinícolas del Valle de Guadalupe, Baja California, Parras de la Fuente, Coahuila y Ezequiel Montes en Querétaro. Este patógeno cuenta con numerosos hospedantes, en algunos de ellos sin causar enfermedad, aunque representa una fuente importante de inóculo, y en otros, causa decaimiento, clorosis, marchitez e inclusive la muerte de la planta. A pesar del daño potencial que puede causar, no hay reportes de la cuantificación de pérdidas, presencia y distribución de hospedantes en México, lo cual es esencial para desarrollar estrategias de manejo. El objetivo de este trabajo fue determinar, mediante sistemas de información geográfica, la presencia y distribución regional y altitudinal de plantas silvestres hospedantes en México.

Métodos: Se elaboró una base de 7695 datos georreferenciados de plantas reportadas en la literatura como hospedantes silvestres de $X$. fastidiosa subsp. fastidiosa, obtenidos de ejemplares herborizados. La información se analizó mediante Sistemas de Información Geográfica para determinar la distribución de especies por estado, regiones fisiográficas, rangos altitudinales, latitudinales y longitudinales.

Resultados clave: Se identificaron 26 especies de plantas silvestres reportadas como hospedantes de $X$. fastidiosa subsp. fastidiosa, ampliamente distribuidas en los 32 estados de la República Mexicana. En los estados de México, Veracruz y Sonora se registró el mayor número de sitios con presencia de especies. Las plantas habitan en un gradiente altitudinal de 0 a 4146 m s.n.m. y se concentran en la provincia fisiográfica del Eje Neovolcánico.

Conclusiones: En México existen las condiciones para el desarrollo de plantas silvestres hospedantes de $X$. fastidiosa subsp. fastidiosa, en especial en la zona de transición del Eje Neovolcánico, en el Estado de México, Ciudad de México, Durango, Michoacán y Veracruz.

Palabras clave: enfermedad de Pierce, especies introducidas, especies silvestres, malezas, SIG.

\begin{abstract}
:
Background and Aims: Xylella fastidiosa subsp. fastidiosa, the causal agent of Pierce's disease, is a $\gamma$-proteobacterium, native to America and present in Mexico in wine-growing areas of the Valle de Guadalupe, Baja California, Parras de la Fuente, Coahuila and Ezequiel Montes in Querétaro. This pathogen has numerous hosts, in some of them without causing disease but representing an important source of inoculum, while in others, it causes decay, chlorosis, wilting and even death of the plant. Despite the potential damage it can cause, there are no reports of the quantification of losses, presence and distribution of hosts in Mexico, which is essential to develop management strategies. The objective of this work was to determine by means of Geographic Information Systems, the presence and regional and altitudinal distribution of host wild plants in Mexico.

Methods: A base of 7695 georeferenced data of plants reported in the literature as hosts of $X$. fastidiosa subsp. fastidiosa obtained from herbalized specimens was developed. The information was analyzed using Geographic Information Systems to determine the distribution of species by state, physiographic regions, altitudinal, latitudinal, and longitudinal ranges.

Key results: Twenty six reported wild plant species were identified as wild hosts of $X$. fastidiosa subsp. fastidiosa, widely distributed in the 32 states of the Mexican Republic. The largest number of sites with species presence was recorded in the states of Mexico, Veracruz, and Sonora. The plants inhabit an altitudinal gradient of 0 to $4146 \mathrm{~m}$ a.s.l. and are concentrated in the physiographic province of the Trans-Mexican Volcanic Belt.

Conclusions: In Mexico, there are conditions for the development of species of wild host plants of $X$. fastidiosa subsp. fastidiosa, especially in the area of transition of the Trans-Mexican Volcanic Belt, in the State of Mexico, Mexico City, Durango, Michoacán and Veracruz.
\end{abstract}

Key words: introduced species, GIS, Pierce's disease, weeds, wild species.

${ }^{1}$ Colegio de Postgraduados, Posgrado en FitosanidadFitopatología, carretera México-Texcoco km 36.5, Montecillo, 56230 Texcoco, Estado de México, México.

${ }^{2}$ Colegio de Postgraduados, Posgrado en FitosanidadEntomología y Acarología, carretera México-Texcoco km 36.5, Montecillo, 56230 Texcoco, Estado de México, México.

${ }^{3}$ Servicio Nacional de Sanidad e Inocuidad y Calidad Agroalimentaria (SENASICA) - Centro Nacional de Referencia Fitosanitaria, carretera Federal México-Pachuca km 37.5, 55740 Técamac, Estado de México, México. ${ }^{4}$ Autor para la correspondencia: oliva_magy@hotmail. com
Recibido: 13 de febrero de 2020 Revisado: 10 de marzo de 2020

Aceptado por Marie-Stéphanie Samain: 25 de mayo de 2020

Publicado Primero en línea: 07 de septiembre de 2020

Publicado: Acta Botanica Mexicana 127 (2020).
Citar como: Oliva-Hurtado, M. M., D. Téliz-Ortiz, L. D. Ortega-Arenas y A. Quezada-Salinas. 2020. Distribución de plantas hospedantes silvestres de Xylella fastidiosa subsp. fastidiosa en México. Acta Botanica Mexicana 127: e1676. DOI: 10.21829/abm127.2020.1676 


\section{Introducción}

Xylella fastidiosa subsp. fastidiosa (Wells) Schaad es el agente causal de la enfermedad de Pierce en distintas plantas; es una $\gamma$-proteobacteria (Gram negativa, con una pared celular formada principalmente de lipopolisacáridos) patogénica que infecta el xilema, disminuye la capacidad de absorción y transporte de agua y nutrientes; en infecciones crónicas provoca la muerte (Sun et al., 2013; Blanco, 2014; Almeida, 2016). La susceptibilidad de los hospedantes es variable; en algunos cultivares los síntomas surgen en los primeros dos años después de la infección (Luck et al., 2010). Plantas infectadas de Vitis vinifera L. mueren en un período de dos a cinco años; al contrario de $V$. labrusca L. que vive más de cinco años después de la infectación (Goodwin y Purcell, 1992). La principal vía de dispersión de la bacteria es a través de insectos vectores de la familia Cicadellidae (Almeida et al., 2005; SENASICA, 2019). EI insecto adquiere la bacteria al momento de alimentarse de una planta infectada, ésta se multiplica y persiste en el intestino de la chicharrita (vector) y la transmite al momento de alimentarse nuevamente (Janse y Obradovic, 2010; Backus y Morgan, 2011; Blanco, 2014). Una vez adquirida la bacteria, los insectos adultos son infectivos a lo largo de su vida (Redak et al., 2004). En California, Estados Unidos de América, la enfermedad de Pierce redujo el rendimiento de almendros en $20-40 \%$ (Sisterson et al., 2012) y $9 \%$ de los árboles infectados murieron en siete años. En cultivos de café en Brasil el aumento de $1 \%$ en la incidencia de la enfermedad causó la pérdida de hasta 60 kg por hectárea (Rocha et al., 2006).

De acuerdo con la Norma Internacional para Medidas Fitosanitarias (NIMF) No. 5, "Glosario de términos fitosanitarios" (IPPC, 2019), Xylella fastidiosa subsp. fastidiosa cumple con la definición de plaga cuarentenaria, ya que esta plaga se encuentra presente en México y puede potencialmente causar pérdidas económicas en cultivos hospedantes por lo que se encuentra bajo control oficial (IPPC, 2019; SENASICA, 2019).

Actualmente, esta bacteria se encuentra presente y confinada en plantaciones de vid ubicadas en los municipios de Ensenada, Baja California, Parras de la Fuente, Coahuila y Ezequiel Montes, Querétaro, los cuales han sido notificados como áreas de riesgo (DOF, 2015; SENASICA,
2017). Aunado a ello, el panel de sanidad vegetal de la European Food Safety Authority (EFSA, 2015) elaboró una lista de plantas silvestres hospedantes de $X$. fastidiosa a nivel mundial con base en revisión de literatura científica, como parte de una evaluación del análisis de riesgo de esta bacteria para el territorio europeo (SENASICA, 2019), en donde reporta como hospedantes de la bacteria a 75 especies: 33 de forma natural y 42 de forma experimental. Entre los cultivos susceptibles a la bacteria se encuentran la vid (Vitis vinifera) como principal hospedante, alfalfa (Medicago sativa L.), café (Coffea arabica L.), durazno (Prunus persica L.), naranja (Citrus sinensis L.) y romero (Rosmarinus officinalis L.). Además, también se ha observado en especies forestales como el maple (Acer spp.), almendro (Prunus dulcis Mill.), nogal (Juglans regia L.), magnolia (Magnolia grandiflora L.), rosa laurel (Nerium oleander L.), sauco (Sambucus sp.), retama de olor (Spartium junceum L.) y 26 especies arvenses silvestres.

Los Sistemas de Información Geográfica (SIG) aplicados al análisis de la distribución geográfica de las plantas silvestres hospedantes de una bacteria fitopatógena son importantes, ya que con los SIG es posible identificar áreas con riesgo de establecimiento de reservorios y dispersión de la bacteria, porque su modelado permite visualizar patrones de distribución, diversidad y concentración de especies (Hijmans y Spooner, 2001; Parthasarathy et al., 2006; Scheldeman et al., 2007). También son empleados para analizar características morfológicas en espacios geográficos (Sunil et al., 2009; Abraham et al., 2010), riqueza de especies de plantas vasculares (Cruz-Cárdenas et al., 2013), monocotiledóneas geófitas (Sosa y Loera, 2017), así como modelos de nicho ecológico de Toxostoma rufum (Linnaeus, 1758), Bubulcus ibis (Linnaeus, 1758), Anoplophora glabripennis (Motschulsky, 1853), Anoplophora malasiaca (Forster, 1771) (Townsend y Vieglais, 2001), potencial invasivo de Xyleborus glabratus (Eichhoff, 1877) y Euwallacea sp. (Lira-Noriega et al., 2018), Hydrilla verticillata (L. f.) Royle y Anoplophora glabripennis (Motschulsky, 1853) (Townsend, 2003).

Conocer el área de mayor diversidad de hospedantes silvestres en México para la bacteria X. fastidiosa subsp. fastidiosa es de gran importancia para diseñar estrategias de manejo y con ello evitar la dispersión de la bacteria en el te- 
rritorio mexicano hacia hospedantes agrícolas de importancia económica como vid, alfalfa, maple, almendro, café, durazno y naranja. Por lo tanto, el objetivo de este estudio fue identificar la distribución y diversidad de especies vegetales reportadas como hospedantes de la bacteria y encontrar patrones de distribución con base en su altitud.

\section{Materiales y Métodos}

Se elaboró una base de datos de las especies hospedantes de $X$. fastidiosa subsp. fastidiosa reportadas por la EFSA (2018), con los siguientes tres tipos de información: 1) referencias bibliográficas (Villaseñor y Espinosa-García, 1998, 2004; Rzedowski y Rzedowski, 2004; Júarez-Jaimes et al., 2008; Vibrans, 2009, 2012; Vargas-Ponce et al., 2017); 2) ejemplares de herbarios depositados en colecciones biológicas, Herbario Nacional de México (MEXU) (UNAM, 2019); y 3) ejemplares del Sistema Nacional de Información sobre Biodiversidad (SNIB, 2019) (museos, colectas y proyectos).

La información se capturó y clasificó de acuerdo con su categoría taxonómica, distribución geográfica, ecológica y curatorial. La sección taxonómica incluyó familia, nombre y autor de la especie. La sección geográfica agrupó el país, estado, municipio, localidad, altitud, latitud y longitud. La sección ecológica incluyó su tipo de vegetación, hábitat, observaciones y fecha de colecta. La información curatorial incluyó el nombre del herbario, del colector, número de co- lecta y nombre del determinador. En aquellos casos en que los registros no contaban con datos de georreferenciación, se infirieron con la descripción de la localidad. La latitud y longitud se estimaron empleando el programa Google Earth (2018). Posteriormente, los valores inferidos se integraron a la base de datos en grados decimales.

\section{Procesamiento de datos}

Los datos geográficos se procesaron en el programa SIG ArcGIS ArcMap 10.1 (ESRI, 2012). La base de datos se transformó a un formato compatible con un SIG mediante ArcMap 10.1. (ESRI, 2012). El procedimiento consistió en la utilización de las coordenadas de latitud y longitud de cada registro, para generar una capa shapefile de punto dentro del SIG asociado con la información contenida en la base. EI resultado final fue un archivo de puntos de todos los registros, o shapefile con la información de la especie, estado, latitud, longitud y altitud correspondiente a cada punto.

Análisis de variedad de hospedantes por división política, provincia fisiográfica y aspectos geográficos

Se analizaron 7695 registros que representan a 26 especies vegetales silvestres reportadas como hospedantes de $X$. fastidiosa subsp. fastidiosa (Fig. 1A). Para calcular la variedad de especies por división política se contabilizó el núme-

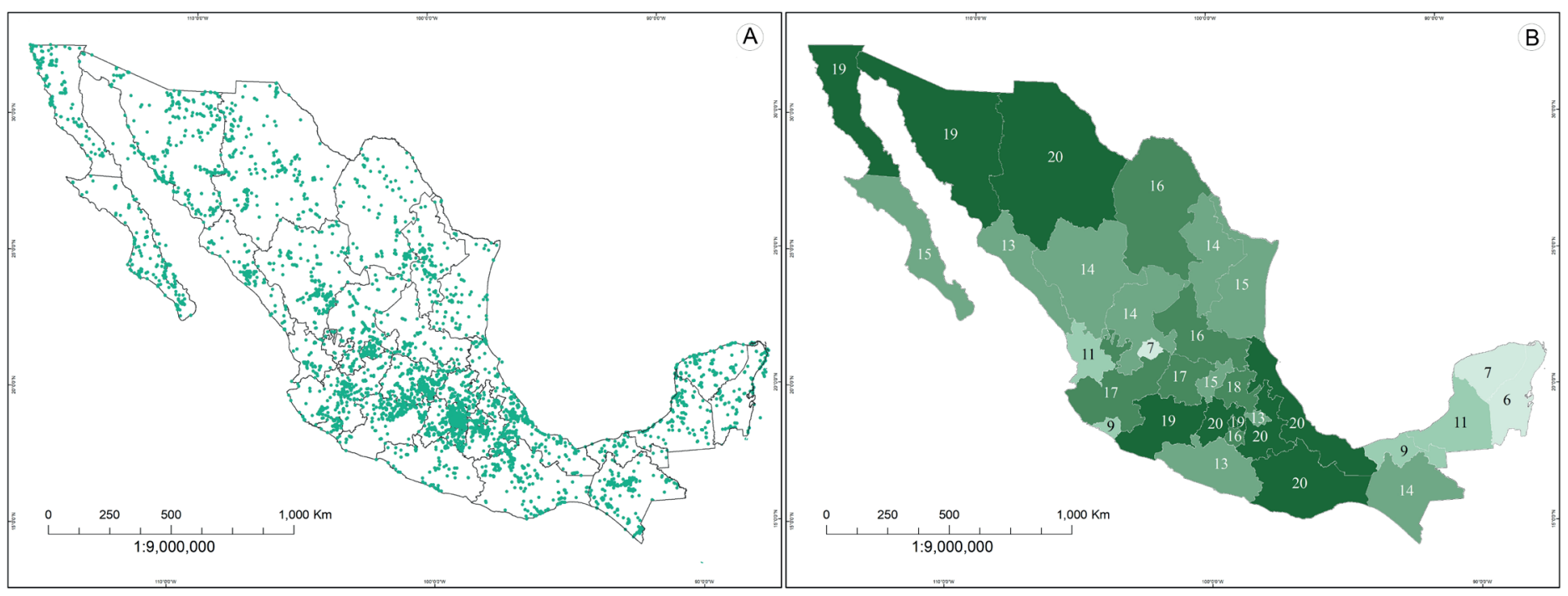

Figura 1: Mapas de distribución y diversidad de especies de plantas silvestres hospedantes de Xylella fastidiosa subsp. fastidiosa (Wells) Schaad en México. A. puntos de ocurrencia; B. diversidad de especies por división política. 
ro de especies y registros en cada estado (Fig. 1B). Para el cálculo de la diversidad de especies por provincia fisiográfica se contabilizó el número de especies localizadas en cada provincia (INEGI, 2001) (Fig. 2). Así mismo, para caracterizar la distribución de las especies según su distribución geográfica (latitud, longitud y altitud), se contabilizó la amplitud en la que se distribuyen (Fig. 3).

\section{Análisis de la densidad de sitios por cuadrícula} Para el análisis de la densidad de sitios por cuadrícula se utilizó el programa ArcGIS 10.1 (ESRI, 2012) para dividir la superficie de México en celdas de $30 \times 30 \mathrm{~km}$. En total se obtuvieron 1179 celdas con ocurrencia de sitios con hospedantes; se asignó la información contenida en el archivo de puntos y se estimó la densidad.

\section{Resultados}

\section{Base de datos y georreferenciación}

La base de datos se conformó con 8012 registros, pero 317 se excluyeron por ser colectas realizadas fuera de México y/o tener información confusa e incompleta. El análisis final se realizó con 7695 registros de plantas silvestres hospedantes de $X$. fastidiosa subsp. fastidiosa, de los cuales $96.7 \%$ (7446) fueron georreferenciados.
Diversidad de especies botánicas por división política

Las 26 especies vegetales reportadas como hospedantes de $X$. fastidiosa subsp. fastidiosa reportadas por la EFSA (2018) tuvieron presencia en los 32 estados de México (Cuadros 1, 2). Su distribución geográfica fue irregular. En Chihuahua, Estado de México, Oaxaca, Puebla y Veracruz se concentró el mayor número de especies (Cuadro 2, Fig. 1B), mientras que Quintana Roo, Aguascalientes y Yucatán presentaron el menor número de especies. El Estado de México, Veracruz, Sonora, Michoacán, Durango, Chihuahua, Oaxaca, Chiapas, Puebla, Baja California Sur, y Ciudad de México tuvieron más sitios con presencia de hospedantes, que en conjunto corresponden con $52 \%$ de los registros. Sorghum halepense (L.) Pers., Ipomoea purpurea (L.) Lam., Cyperus esculentus L. y Echinochloa crus-galli (L.) P. Beauv. fueron las especies con mayor distribución, pues estuvieron presentes en 1077 sitios y 32 estados, 947 (30), 702 (31) y 664 (28), respectivamente. Por el contrario, Ambrosia acanthicarpa Hook., Datura wrightii Regel, Simmondsia chinensi (Link) C.K. Schneid. y Amaranthus blitoides $\mathrm{S}$. Watson se encontraron en menos de seis estados (Cuadro 2, Fig. 2).

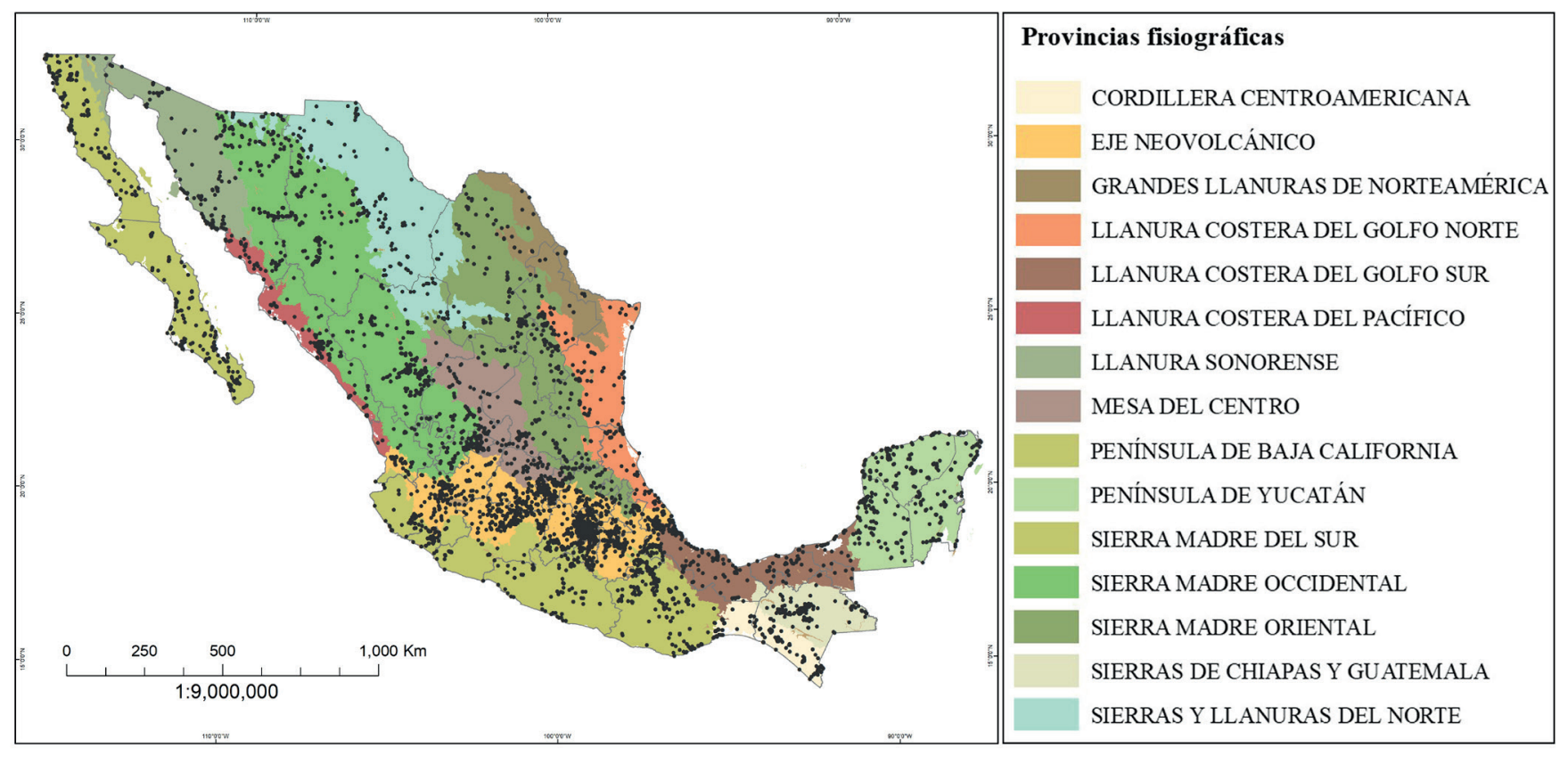

Figura 2: Distribución de hospedantes de Xylella fastidiosa subsp. fastidiosa (Wells) Schaad en México por provincia fisiográfica. 

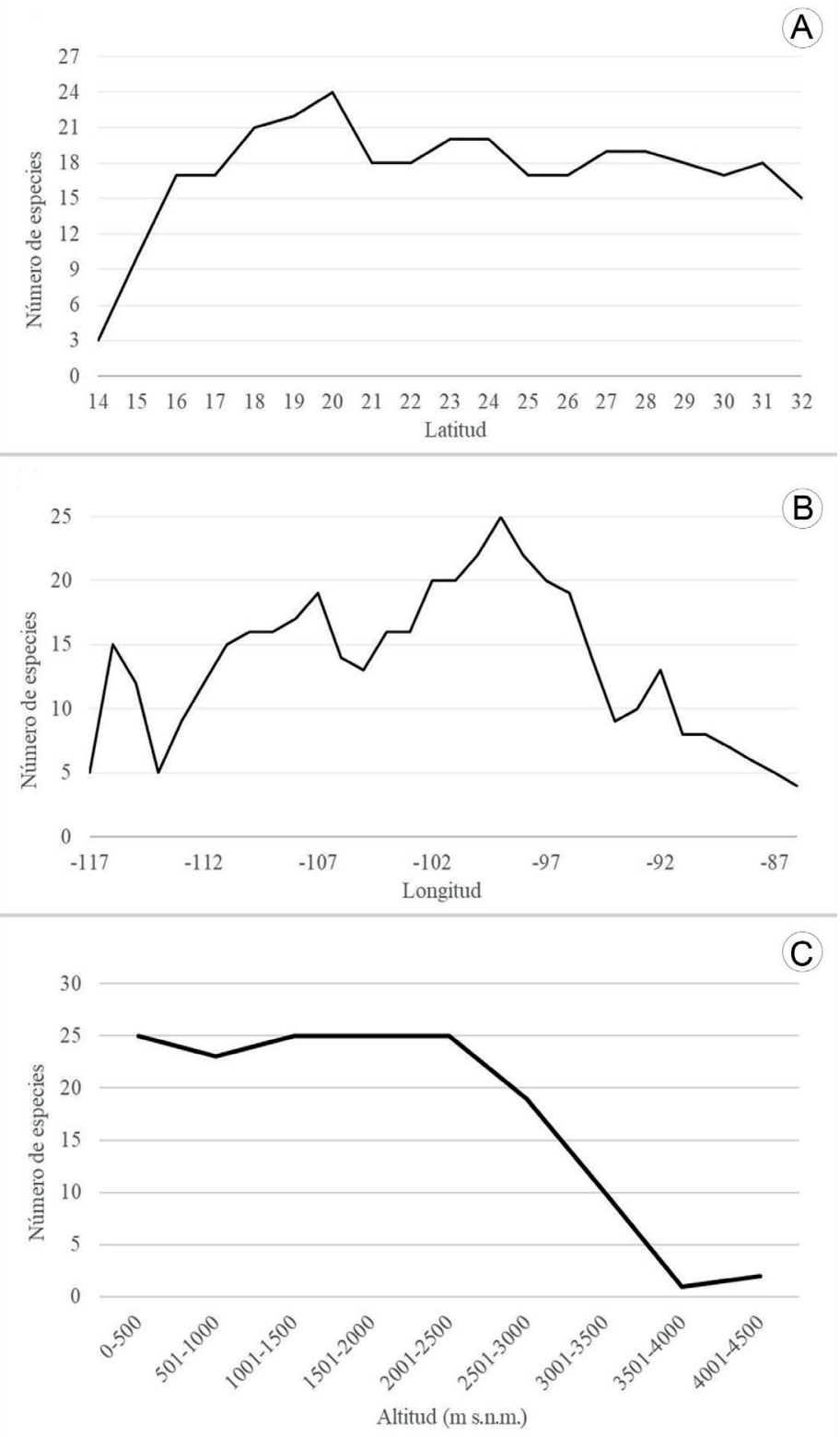

Figura 3: Número de hospedantes de Xylella fastidiosa subsp. fastidiosa (Wells) Schaad en México por criterios geográficos. A. latitud; B. longitud; C. altitud.

Número de especies hospedantes por provincias fisiográficas

La provincia del Eje Neovolcánico (abarca porciones de los estados de Nayarit, Jalisco, Michoacán, Guanajuato, Querétaro, Estado de México, Tlaxcala, Ciudad de México, Morelos, Puebla y Veracruz) albergó 24 de las 26 especies hospedantes de $X$. fastidiosa subsp. fastidiosa, mientras que la Sierra Madre Occidental 21, Sierra Madre Oriental 21, Península de Baja California 20, Sierra Madre del Sur
19. Llanura Sonorense y Sierras y Llanuras del Norte 17, Mesa del Centro 16, y Llanura Costera del Golfo Norte 15. En contraste, en la provincia fisiográfica de la Península de Yucatán se registraron 10 especies y en Grandes Llanuras de Norteamérica solo se registraron ocho.

En la zona del Eje Neovolcánico se registró el mayor número de sitios con hospedantes (2464 sitios (33.1\%)), seguida de la Sierra Madre Occidental con 1045 sitios (14\%), Sierra Madre del Sur con 775 (10.4\%), Península de Yucatán con 512 (6.9\%), Sierra Madre Oriental con 464 (6.2\%), Península de Baja California con 375 (5\%) y Llanura Costera del Golfo Sur con 314 sitios (4.2\%). El restante $20 \%$ se encontró en las demás provincias fisiográficas. Las especies con mayor distribución fueron Conyza canadensis (L.) Cronquist y Sorghum halepense presentes en 15 provincias biogeográficas. Cyperus esculentus, Ipomoea purpurea, Portulaca oleracea L. y Xanthium strumarium L. se encontraron en 14 provincias, mientras que Ambrosia acanthicarpa y Eucalyptus globulus Labill. solo en dos (Fig. 4).

\section{Distribución de plantas silvestres hospedantes por ubicación geográfica}

Las plantas silvestres hospedantes de $X$. fastidiosa subsp. fastidiosa crecen en un gradiente de 0 a $4146 \mathrm{~m}$ de altitud (Fig. 3C), y entre $14^{\circ}$ a $32^{\circ}$ de latitud norte (Fig. 3A) y $87^{\circ}$ a $117^{\circ}$ longitud oeste (Fig. 3B). De las 26 especies registradas, 23 se encontraron entre 0 a 3500 m s.n.m., y solo tres entre 3500 y 4146 m s.n.m. (Fig. 3C). Conium maculatum L. fue la especie con mayor amplitud altitudinal (155-4031 m s.n.m.) y está presente en 11 estados. Caso contrario, Datura wrightii presentó la amplitud altitudinal más restringida (83-1899 m s.n.m.) y Vicia sativa L. se encontró por arriba de 1099 m s.n.m. (Fig. 5).

\section{Densidad de sitios con especies hospedantes por cuadricula}

El territorio de México se dividió en una reticula compuesta de celdas, 1179 tuvieron al menos un registro (Fig. 6). El número de sitios por celda varió de 1 a 224. Se encontraron casos de una celda con 224 sitios, 183, 107 y 101 sitios, 64 celdas de 95 a 20 registros, siete celdas con 19, seis celdas con 18,11 celdas con 17 , siete con 16,12 con 15,15 con 14 , 18 con 13, nueve con 12, 14 con 11, 17 con 10, 27 con nue- 
Cuadro 1: Hospedantes de Xylella fastidiosa subsp. fastidiosa (Wells) Schaad, con registros georreferenciados en el Herbario Nacional MEXU. * Maleza (Villaseñor y Espinosa-García, 1998), **Especie silvestre (especie endémica del desierto de Sonora, se asocia con Yucca sp. (Vázquez-Yanes et al., 1999)), *** Especie introducida. Fuentes: UNAM, 2019 y CONABIO, 2019.

\begin{tabular}{|c|c|c|c|}
\hline Especie & CONABIO & MEXU & Sitios \\
\hline Sorghum halepense (L.) Pers.* & 905 & 172 & 1,077 \\
\hline Ipomoea purpurea (L.) Roth* & 937 & 10 & 947 \\
\hline Cyperus esculentus L.* & 600 & 102 & 702 \\
\hline Echinochloa crus-galli (L.) P. Beauv.* & 614 & 50 & 664 \\
\hline Portulaca oleracea L.* & 490 & 155 & 645 \\
\hline Conyza canadensis (L.) Cronquist* & 467 & 112 & 579 \\
\hline Xanthium strumarium L.* & 365 & 173 & 538 \\
\hline Rumex crispus L.* & 427 & 61 & 488 \\
\hline Catharanthus roseus (L.) G. Don* & 297 & 20 & 317 \\
\hline Eriochloa acuminata J. Presl * & 246 & - & 246 \\
\hline Simmondsia chinensis (Link) C.K. Schneid. ** & 142 & 88 & 230 \\
\hline Nicotiana glauca Graham* & - & 158 & 158 \\
\hline Vicia sativa L.* & 139 & 19 & 158 \\
\hline Eucalyptus globulus Labill.*** & 145 & 3 & 148 \\
\hline Helianthus annuus L.* & - & 122 & 122 \\
\hline Lactuca serriola L.* & 101 & 18 & 119 \\
\hline Ambrosia artemisiifolia L.* & 110 & 2 & 112 \\
\hline Eucalyptus camaldulensis Dehnh. ${ }^{* * *}$ & 92 & 8 & 100 \\
\hline Convolvulus arvensis L.* & 61 & 12 & 73 \\
\hline Conium maculatum L.* & 60 & 8 & 68 \\
\hline Erodium moschatum (L.) L'Hér. * & 52 & 9 & 61 \\
\hline Malva parviflora L.* & - & 56 & 56 \\
\hline Chrysanthemum morifolium Ramat.*** & 33 & 4 & 37 \\
\hline Ambrosia acanthicarpa Hook.** & 26 & 2 & 28 \\
\hline Amaranthus blitoides S. Watson * & 9 & 2 & 11 \\
\hline Datura wrightii Regel* & - & 11 & 11 \\
\hline
\end{tabular}

ve, 41 con ocho, 43 con siete, 52 con seis, 71 con cinco, 119 con cuatro, 129 con tres, 185 con dos y 326 celdas con un solo sitio. El área con mayor densidad de sitios se localizó en el centro del país, entre el Estado de México y la Ciudad de México, así como en el centro de Durango, centro de Veracruz y norte de Michoacán (Fig. 6).

\section{Discusión}

Los Sistemas de Información Geográfica empleados en el presente estudio fueron útiles para ubicar la presencia, distribución regional y distribución altitudinal de hospedantes de $X$. fastidiosa subsp. fastidiosa en México. A través de esta herramienta se pudo verificar que las 26 especies vegetales reportadas como hospedantes de $X$. fastidiosa por la EFSA
(2018) tuvieron presencia en los 32 estados de México. Este hallazgo indica que la bacteria cuenta con hospedantes donde albergarse, lo que aumenta la probabilidad de dispersión de la enfermedad a nivel nacional. También fue evidente en este estudio que la mayoría de las hospedantes de la bacteria crecen en amplios gradientes altitudinales y se concentran en la provincia fisiográfica del Eje Neovolcánico que abarca los estados de México y Ciudad de México, norte de Michoacán, centro sur de Querétaro, sur de Guanajuato, centro de Veracruz, sur de Durango, centro de Chihuahua, noroeste de Oaxaca, oeste de Puebla y centro de Jalisco, lo que favorece la disponibilidad de sitios de refugio y alimentación permanentes, muchos de los cuales sirven como fuentes alternativas de alimento para posibles 
Cuadro 2: Distribución geográfica de sitios con hospedantes de Xylella fastidiosa subsp. fastidiosa (Wells) Schaad por estado en México. Elaboración propia con datos de UNAM (2019) y CONABIO (2019). Los números indican los registros por estado.

\begin{tabular}{|c|c|c|c|c|c|c|c|c|c|c|c|c|c|c|c|c|c|c|c|c|c|c|c|c|c|c|c|c|}
\hline $\begin{array}{l}\text { Estado / } \\
\text { Especies }\end{array}$ & 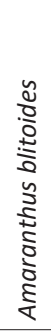 & 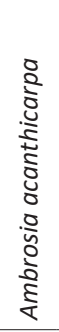 & 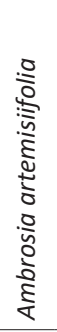 & 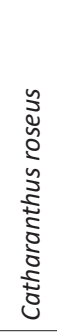 & 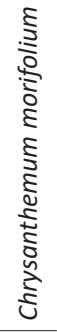 & 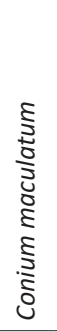 & 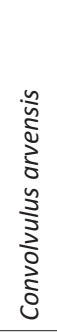 & 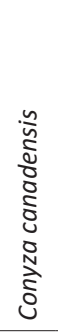 & 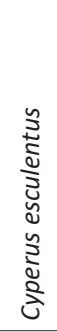 & 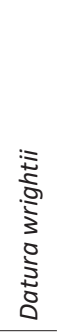 & 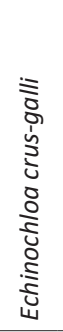 & 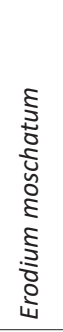 & 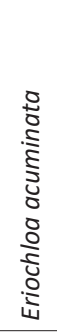 & 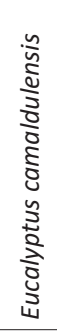 & 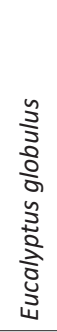 & 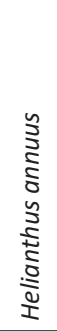 & 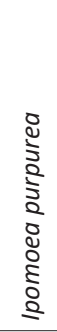 & 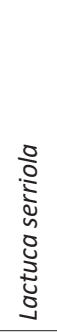 & $\begin{array}{l}0 \\
0 \\
\frac{0}{5} \\
\frac{5}{3} \\
0 \\
0 \\
0 \\
\frac{1}{0} \\
\sum\end{array}$ & 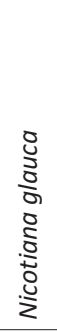 & 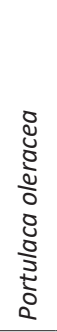 & 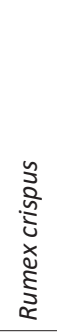 & 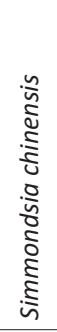 & 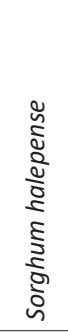 & 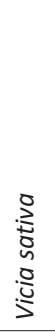 & 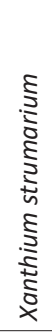 & 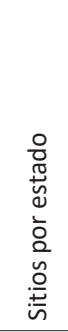 & 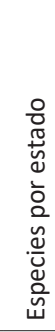 \\
\hline Aguascalientes & & & & & & & & 1 & & & 31 & & & & & & 59 & & & 14 & & 10 & & 3 & & 2 & 120 & 7 \\
\hline Baja California & 4 & 2 & 2 & & & & 5 & 19 & 1 & 2 & 9 & 7 & 1 & 2 & & & & 7 & 2 & 4 & 4 & 11 & 94 & 4 & & 9 & 189 & 19 \\
\hline $\begin{array}{l}\text { Baja California } \\
\text { Sur }\end{array}$ & & 1 & & & & 1 & 1 & 15 & 38 & & & 1 & 26 & & & & 16 & 1 & 1 & 4 & 9 & & 86 & 7 & & 7 & 214 & 15 \\
\hline Campeche & & & & 41 & & & & 29 & 13 & & 3 & & 1 & 1 & & 2 & 1 & & 1 & & 41 & & & 75 & & & 208 & 11 \\
\hline $\begin{array}{l}\text { Ciudad de } \\
\text { México }\end{array}$ & & & 2 & 1 & & 33 & 1 & 28 & 21 & & 19 & 6 & & 14 & 7 & 2 & 21 & 2 & 7 & 4 & 17 & 18 & & 4 & 18 & & 225 & 19 \\
\hline Chiapas & & & 4 & 24 & 3 & & & 64 & 29 & & 3 & 16 & & 22 & 14 & & 29 & & & & 47 & 27 & & 47 & & & 339 & 14 \\
\hline Chihuahua & 1 & 14 & 21 & & & 5 & 1 & 20 & 29 & 2 & 57 & & 47 & 1 & & 20 & 28 & 4 & 2 & & 15 & 40 & 2 & 38 & & & 377 & 20 \\
\hline Coahuila & 2 & & 2 & & & & 1 & 5 & 7 & 1 & 21 & & 2 & & & 16 & 18 & 12 & & 6 & & 17 & & 66 & 1 & & 199 & 16 \\
\hline Colima & & & & 3 & & & & 2 & 12 & & 5 & & & & & & 8 & & 1 & & & 1 & & 22 & & 2 & 56 & 9 \\
\hline Durango & & & 5 & & & 1 & & 11 & 44 & & 80 & & 37 & 9 & & & 42 & & 8 & 14 & 19 & 23 & & 54 & & & 394 & 14 \\
\hline Guanajuato & & & 2 & & & & 4 & 4 & 34 & & 42 & 2 & 23 & 3 & 4 & 6 & 39 & 14 & & 4 & 7 & 11 & & 22 & & & 250 & 17 \\
\hline Guerrero & & & & 2 & 2 & & & 6 & 13 & & 2 & & 2 & & & & 25 & 1 & & 4 & 21 & 3 & & 24 & & 5 & 110 & 13 \\
\hline Hidalgo & 1 & & & 1 & & 6 & 4 & 12 & 27 & & 10 & 5 & & & & & 28 & 2 & 2 & 2 & 16 & 16 & 1 & 6 & 15 & 7 & 161 & 18 \\
\hline Jalisco & & & 4 & 19 & & & 1 & 3 & 41 & & 72 & & 12 & 7 & 2 & 2 & 16 & 4 & & 10 & 11 & 27 & & 25 & & & 273 & 17 \\
\hline Michoacán & & & & 1 & & 1 & 3 & 39 & 63 & & 60 & 3 & 11 & 6 & 3 & & 72 & 27 & 1 & 6 & 18 & 24 & & 46 & 16 & & 416 & 19 \\
\hline Morelos & & & 1 & 6 & 5 & & & 2 & 3 & & & 1 & 3 & 3 & 7 & & 16 & & 1 & & 5 & 5 & & 11 & 4 & & 87 & 16 \\
\hline México & & & 11 & 5 & & 13 & 7 & 34 & 89 & & 42 & 8 & 2 & 17 & 63 & & & 8 & 4 & 10 & 24 & 70 & & 42 & 88 & & 726 & 20 \\
\hline Nayarit & & & & 1 & & & & 12 & 4 & & 7 & & 1 & & & 2 & 5 & & & 2 & 3 & & & 19 & & 9 & 65 & 11 \\
\hline Nuevo León & & & 10 & & & & 7 & 15 & 1 & & 1 & & & & 3 & 12 & 21 & 6 & 1 & & 5 & 20 & & 53 & & 4 & 159 & 14 \\
\hline Oaxaca & & & 3 & 25 & 3 & & 1 & 36 & 28 & & 1 & 2 & 4 & 1 & 9 & & 36 & 2 & 9 & 28 & 39 & 20 & & 56 & 3 & & 367 & 20 \\
\hline Puebla & & & 4 & 32 & 11 & 2 & 1 & 22 & 21 & & 15 & 3 & 7 & 7 & 3 & & 53 & & 7 & 14 & 34 & 41 & & 16 & 2 & & 325 & 20 \\
\hline Querétaro & & & & & & 1 & 12 & 13 & 21 & & 23 & & 5 & 1 & & & 86 & 7 & & 6 & 16 & 35 & & 32 & 1 & \# & 285 & 15 \\
\hline Quintana Roo & & & & 26 & & & & 29 & 28 & & & & & & & 2 & & & & & 40 & & & 29 & & & 154 & 6 \\
\hline
\end{tabular}


Cuadro 2: Continuación.

\begin{tabular}{|c|c|c|c|c|c|c|c|c|c|c|c|c|c|c|c|c|c|c|c|c|c|c|c|c|c|c|c|c|}
\hline $\begin{array}{l}\text { Estado / } \\
\text { Especies }\end{array}$ & 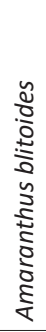 & 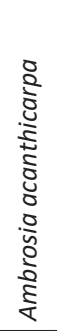 & 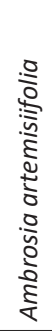 & 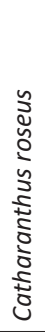 & 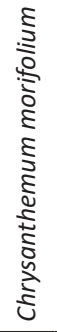 & 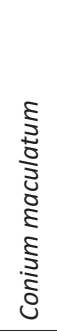 & 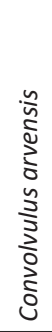 & 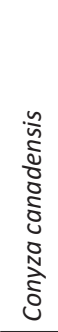 & 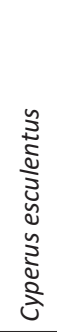 & 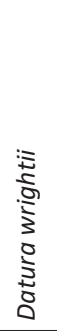 & 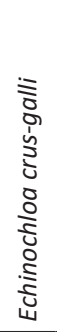 & 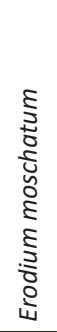 & 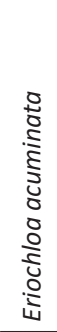 & 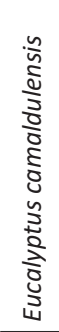 & 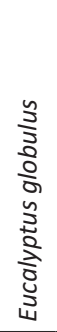 & 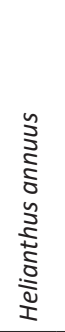 & 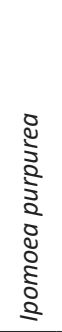 & 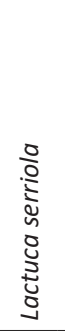 & $\begin{array}{l}0 \\
\frac{1}{0} \\
\frac{5}{2} \\
\frac{1}{0} \\
\frac{0}{0} \\
\frac{0}{0} \\
\sum\end{array}$ & 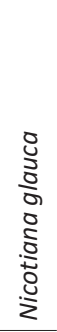 & 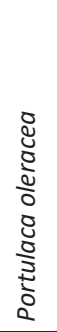 & 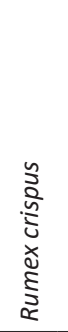 & 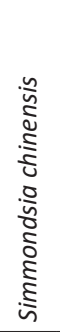 & 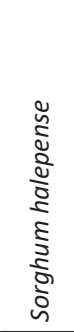 & 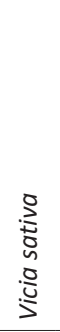 & 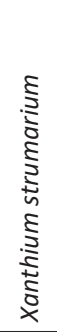 & 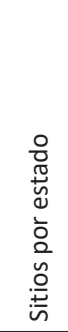 & 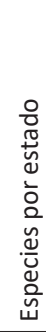 \\
\hline San Luis Potosí & & & 8 & & 6 & & 1 & 6 & 5 & & 17 & 1 & 1 & & 4 & 2 & 13 & & & 2 & 3 & 11 & & 19 & & & 125 & 16 \\
\hline Sinaloa & & & 2 & 4 & & & 2 & 11 & 14 & & 21 & & 4 & & & 10 & 18 & & & & 12 & 9 & & 20 & & & 147 & 13 \\
\hline Sonora & 2 & 11 & & & & & 19 & 32 & 21 & 5 & 54 & & 48 & 2 & & 20 & 22 & 17 & 3 & 12 & 22 & 22 & 47 & 110 & & & 498 & 19 \\
\hline Tabasco & & & 1 & 7 & & & & 4 & 2 & & 5 & & 1 & & & & 10 & & & & 12 & & & 11 & & & 53 & 9 \\
\hline Tamaulipas & 1 & & 5 & 1 & & & & 6 & 20 & 1 & 4 & & 5 & & & 10 & 14 & & & 2 & 8 & 7 & & 44 & & 7 & 135 & 15 \\
\hline Tlaxcala & & & & & & 4 & & 2 & 16 & & 2 & 4 & & 3 & 4 & & 5 & & 2 & & 3 & 8 & & 1 & 4 & & 58 & 13 \\
\hline Veracruz & & & 20 & 57 & 7 & 1 & & 66 & 42 & & 19 & 2 & 2 & 1 & 20 & 8 & 43 & & 4 & 2 & 69 & 4 & & 122 & 6 & & 518 & 20 \\
\hline Yucatán & & & & 61 & & & & 21 & 4 & & & & 1 & & & & 3 & & & & 99 & & & 21 & & & 210 & 7 \\
\hline Zacatecas & & & 5 & & & & 2 & 10 & 11 & & 39 & & & & 5 & 8 & 38 & 5 & & 8 & 26 & 8 & & 28 & & & 252 & 14 \\
\hline
\end{tabular}

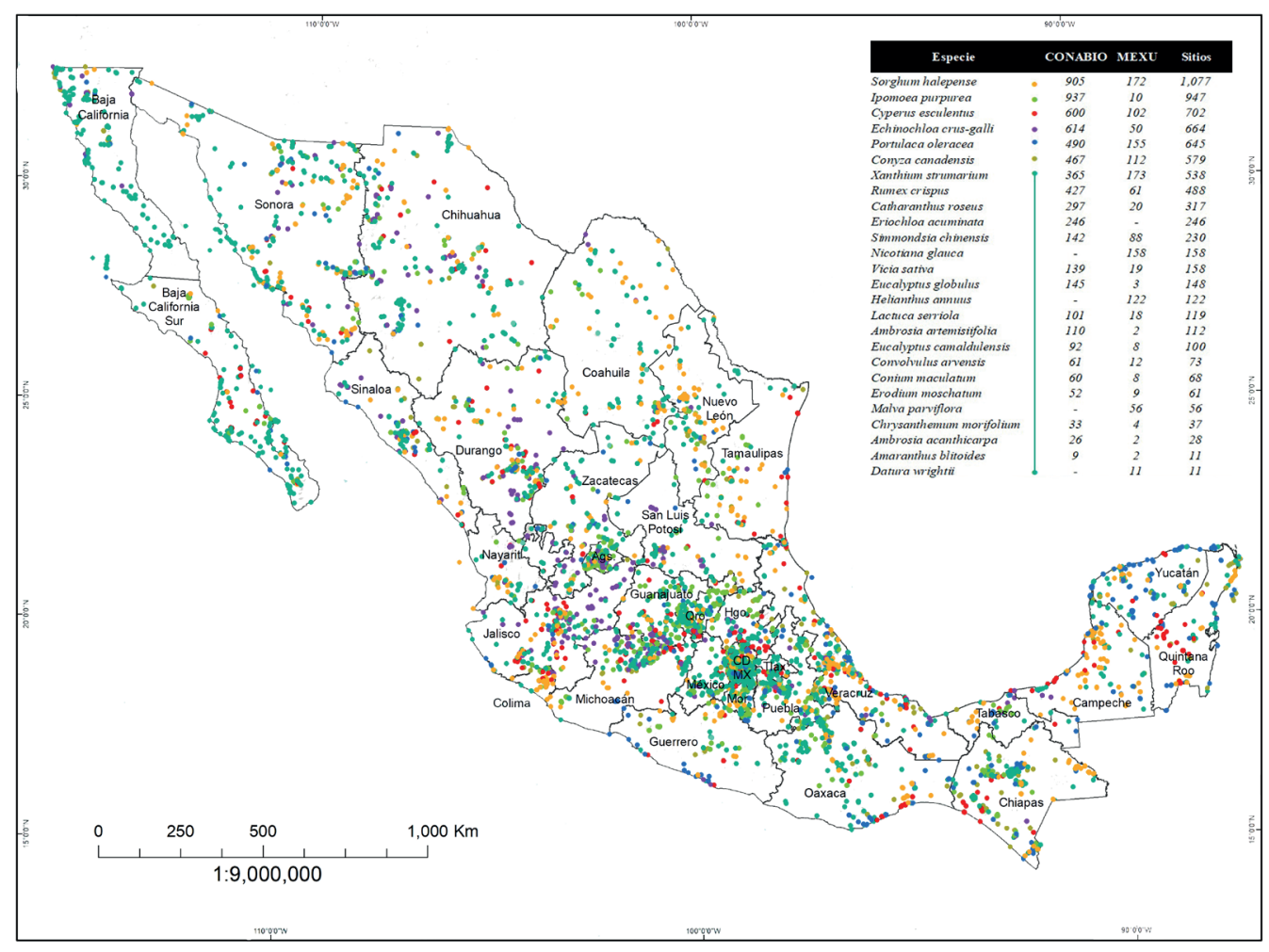

Figura 4: Sitios con presencia de hospedantes de Xylella fastidiosa subsp. fastidiosa (Wells) Schaad en México. 
vectores. Como ejemplo de ello se puede citar al zacate anual Echinochloa crus-galli y a Simmondsia chinensis, especies hospedantes de amplia distribución a nivel nacional, presentes en varios estados (Baja California, Coahuila, Querétaro y Sonora), y que sirven de hospedantes tanto de $X$. fastidiosa como de su vector Xyphon fulgidum Nottingham, 1932 (EFSA, 2018; EPPO, 2019).

Hubo coincidencia respecto a la densidad de sitios con especies hospedantes de $X$. fastidiosa potenciales en México y los principales estados productores de cultivos de importancia económica, como la uva, durazno, café, alfalfa, naranja, y romero (SIAP, 2019). Alrededor de 830 municipios con superficie sembrada de estos cultivos tuvieron registros de sitios de especies silvestres hospedantes (SIAP, 2019), por lo que, tener conocimiento y ubicación de las especies que pueden albergar a la bacteria y la localización municipal de sus insectos vectores permitirá tomar las medidas preventivas necesarias para salvaguardar la producción nacional.

Conocer los hospedantes de la bacteria y su distribución es de gran utilidad porque esto permitiría a las autoridades fitosanitarias redirigir las acciones culturales de la campaña (eliminación de plantas hospedantes de vectores a modo de control preventivo), evitando el aumento en las densidades poblacionales y los nichos de refugio, debido a que los vectores Xyphon fulgidum y Draeculacephala minerva Ball, 1927 no son atraídas por las trampas amarillas (trozo de plástico recubierto por ambos lados de una capa delgada de una sustancia pegajosa que atrae al insecto) (SENASICA, 2018) hacia sitios y hospedantes silvestres específicos. Es decir, se podrían manejar de forma dirigida las especies silvestres que fungen como hospedantes o reservorios tanto para la bacteria como de sus insectos vectores, priorizando las áreas circundantes alrededor de las zonas de mayor producción agrícola de los cultivos hospedantes de importancia económica como: uva, durazno, café, alfalfa, naranja y romero, en los sitios sin presencia de la enfermedad, a modo de control preventivo para evitar el aumento en las densidades poblacionales y los nichos de refugio (SENASICA, 2018).

Es de suma importancia profundizar en el manejo de especies ampliamente distribuidas a nivel nacional como el zacate anual Echinochloa crus-galli y Simmondsia chinensis,

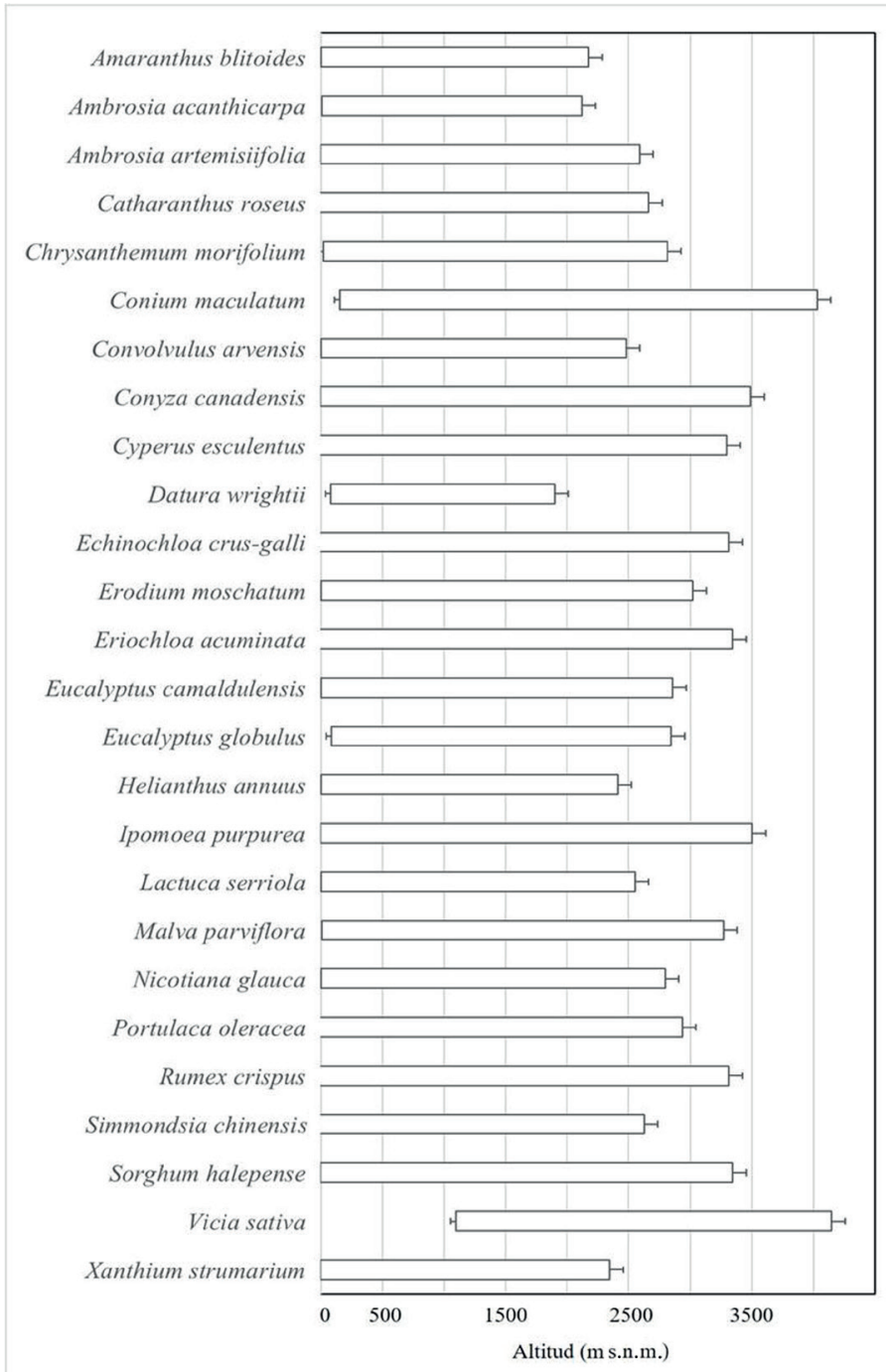

Figura 5: Distribución de hospedantes de Xylella fastidiosa subsp. fastidiosa (Wells) Schaad en México por rangos de altitud.

esto debido a que $E$. crus-galli es una de las cinco especies con mayor distribución a nivel nacional presente en 28 estados (incluye Baja California, Coahuila y Querétaro) y en un total de 664 sitios, esta especie es reportada por EFSA (2018) y EPPO (2019) como hospedante tanto de $X$. fastidiosa como de su vector Xyphon fulgidum, el cual puede fungir como fuente de inóculo para la infección de otros cultivos de importancia económica. Así mismo, Simmondsia chinensis es otra especie con asociación doble, pues es hospedante de $X$. fastidiosa subsp. fastidiosa y a su vez está asociada con la especie Yucca valida Brandegee la cual funge como refugio del vector Homalodisca liturata Ball, 1901 (100 por planta) y esta presente en cinco estados (entre ellos Baja 


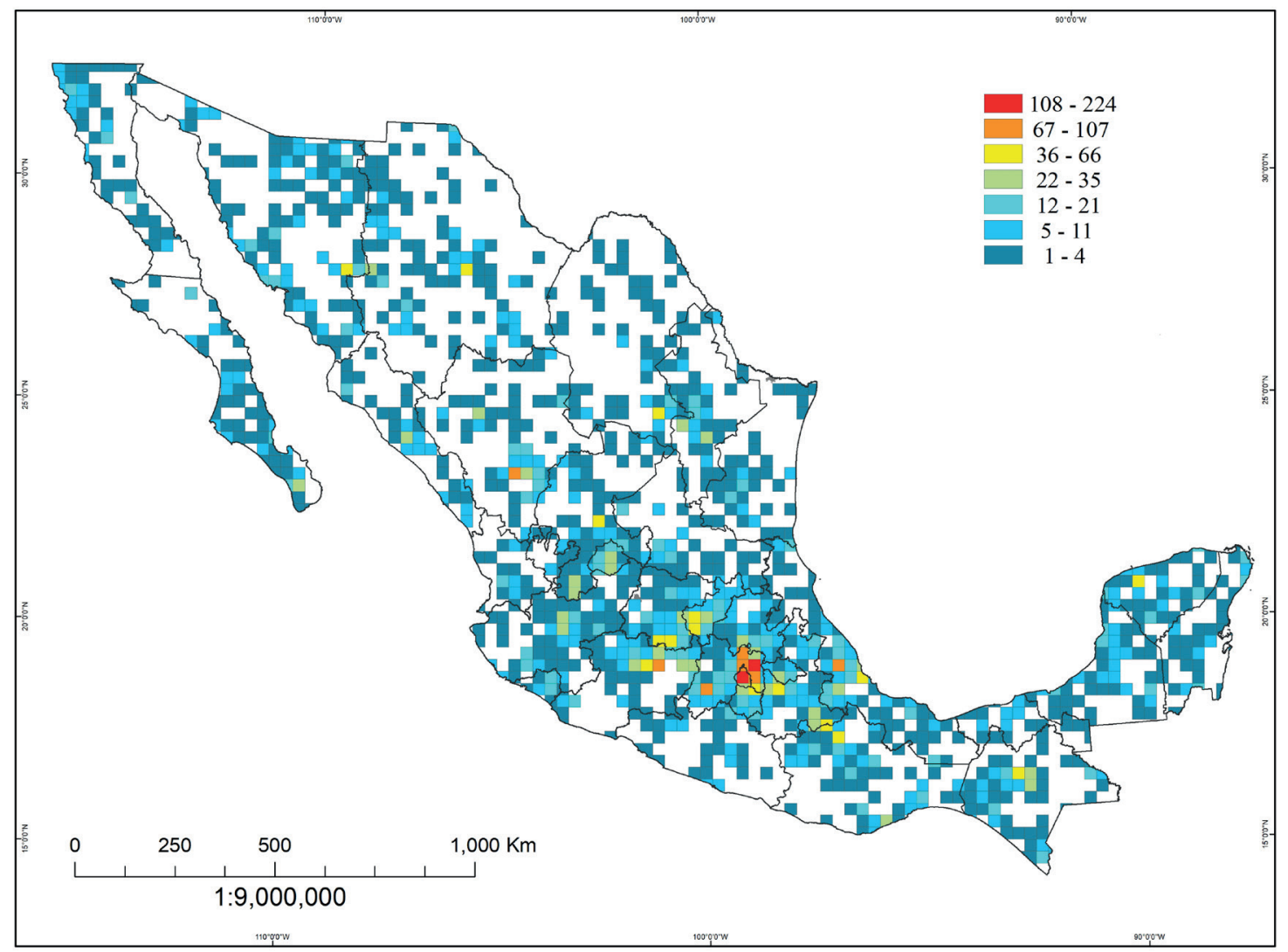

Figura 6: Densidad de sitios con presencia de hospedantes de Xylella fastidiosa subsp. fastidiosa (Wells) Schaad en México por cuadrícula.

California y Sonora), en 230 sitios (Servín-Villegas et al., 2009). Debido a la amplia distribución de estas especies es necesario localizar las áreas en las que convergen tanto las principales zonas productoras de los cultivos de importancia económica, así como los sitios de hospedantes silvestres, detecciones cercanas de la bacteria y de sus insectos vectores, para mitigar el establecimiento de la bacteria en nuevas zonas productoras.

Otra aplicación práctica de la información generada en este estudio es la captura directa de los vectores como Xyphon fulgidum y Draeculacephala minerva que no son atraídos por las trampas amarillas y que se encuentran en hospedantes alternantes como el zacate bermuda (Cynodon dactylon (L.) Pers), zacate de agua (Echinochloa crusgalli) y cultivos leñosos o perennes (Berkeley, 2018; EPPO, 2019; UCANR, 2019), ubicados dentro o en la periferia de los viñedos con presencia de la enfermedad de Pierce (SENASICA, 2018; UCANR, 2019).

De la presente investigación se concluye que en México existen las condiciones necesarias para albergar a di- ferentes hospedantes silvestres de $X$. fastidiosa subsp. fastidiosa en cualquier latitud, longitud y altitud, en especial en la zona del Eje Neovolcánico, en la transición del Estado de México, Ciudad de México, Durango, Michoacán y Veracruz, por tal razón, se recomienda realizar investigaciones de forma local en estas zonas para la corroboración de las especies silvestres hospedantes y de los insectos vectores que se albergan en estas áreas.

\section{Contribución de autores}

MMOH diseñó la investigación, obtuvo datos, analizó y escribió el manuscrito. DTO, LDOA y AQS concibieron la investigación, analizaron y escribieron el manuscrito. Todos los autores contribuyeron a la discusión, revisión y aprobación del manuscrito final.

\section{Financiamiento}

Este estudio fue financiado por el Convenio de Colaboración COLPOS-SENASICA 2017 "Lineas de investigación Nacional en Temas Fitosanitarios". 


\section{Agradecimientos}

Al posgrado de Fitosanidad-Fitopatología del Colegio de Postgraduados (COLPOS) campus Montecillo y al Centro Nacional de Referencia Fitosanitario de la Dirección General de Sanidad Vegetal del Servicio Nacional de Sanidad, Inocuidad y Calidad Agroalimentaria (SENASICA). Tambien extendemos nuestro agradecimiento a los revisores anónimos y al editor por sus comentarios y sugerencias para mejorar el manuscrito.

\section{Literatura citada}

Abraham, B., V. Kamala, N. Sivaraj, N. Sunil, S. R. Pandravada, M. Vanaja y K. S. Varaprasad. 2010. DIVA-GIS approaches for diversity assessment of pod characteristics in black gram (Vigna mungo (L.) Hepper). Current Science 98(5): 616-619.

Almeida, R. P. 2016. Xylella fastidiosa vector transmission biology. In: Brown, J. K. (ed.). Vector-mediated transmission of plant pathogens. American Phytopathological Society Press. Minnesota, USA. Pp. 165-174.

Almeida, R. P., P. Blua, J. Matthew, R. Lopes, S. João y A. H. Purcell. 2005. Vector transmission of Xylella fastidiosa: applying fundamental knowledge to generate disease management strategies. Annals of the Entomological Society of America 98(6): 775-786. DOI: https://doi.org/10.1603/0013-8746(2005)098[0775:vtoxfa]2.0.co;2

Backus, E. A. y D. J. Morgan. 2011. Spatiotemporal colonization of Xylella fastidiosa in its vector supports the role of egestion in the inoculation mechanism of foregut-borne plant pathogens. Phytopathology 101(8): 912-922. DOI: https://doi. org/10.1094/phyto-09-10-0231

Berkeley. 2018. Red-headed sharpshooter. University of California. Berkeley, USA. https://nature.berkeley.edu/xylella/ biology/insect-vectors/red-headed-sharpshooter/ (consultado junio de 2019).

Blanco, R. E. 2014. Cicadélidos (Hemiptera: Cicadellidae) asociados a cítricos en la Península de Yucatán. Tesis de maestría. Colegio de Postgraduados. Texcoco, México. 87 pp.

CONABIO. 2019. Enciclovida. Comisión Nacional para el Conocimiento y Uso de la Biodiversidad. Cd. Mx., México. http://enciclovida.mx/explora-por-region (consultado marzo de 2018).

Cruz-Cárdenas, G., J. L. Villaseñor, L. López-Mata y E. Ortiz. 2013. Distribución espacial de la riqueza de especies de plantas vasculares en México. Revista Mexicana de Biodiversidad 84(4): 1189-1199. DOI: https://doi.org/10.7550/rmb.31811
DOF. 2015. AVISO por el que se dan a conocer las zonas bajo control fitosanitario, por presencia de la Enfermedad de Pierce Xylella fastidiosa subsp. fastidiosa, a la zona vitícola del Valle de Guadalupe, Baja California; Parras de la Fuente, Coahuila de Zaragoza y Ezequiel Montes, Querétaro. Secretaria de Agricultura, Ganadería, Desarrollo Rural, Pesca y Alimentación. Diario Oficial de la Federación. Cd., Mx. México. http://www.dof.gob.mx/nota_detalle. php?codigo $=5382978 \&$ fecha $=23 / 02 / 2015$ (consultado junio de 2019).

EFSA, 2015. Scientific Opinion on the risks to plant health posed by Xylella fastidiosa in the EU territory, with the identification and evaluation of risk reduction options. EFSA Journal 13(1): 3989.DOI: https://doi.org/10.2903/j.efsa.2015.3989

EFSA. 2018. Update of the Xylella spp. host plant database. EFSA Journal 16(9): e05408. DOI: https://doi.org/10.2903/j. efsa.2018.5408

ESRI. 2012. Environmental Scientific Research Institute. ArcGIS 10.1. Software diseñado para análisis espacial y Sistemas de Información Geográfica. Redlands, California, USA. https:// www.esri.com/news/arcnews/spring12articles/introducing-arcgis-101.html (consultado enero de 2018).

EPPO. 2019. Xyphon fulgidum. EPPO Global Database, European and Mediterranean Plant Protection Organization. Paris, France. https://gd.eppo.int/taxon/CARNFU/hosts (consultado enero de 2019).

Goodwin, P. y A. H. Purcell. 1992. Pierce's disease. In: Flaherty, D. L. (ed.). Grape Pest Management. Agriculture and Natural Resources 2nd. Ed. Oakland, USA. Pp. 76-84.

Google Earth. 2018. Google Earth Pro versión 7. https://earth. google.com/web/ (consultado enero de 2018).

Hijmans, R. J. y D. M. Spooner. 2001. Geographic distribution of wild potato species. American Journal of Botany 88(11): 2101-2112. DOI: https://doi.org/10.2307/3558435

INEGI. 2001. Conjunto de datos vectoriales Fisiográficos. Continuo Nacional serie I. Provincias fisiográficas. Escala 1:1, 000,000. https://www.inegi.org.mx/app/mapas/default. html?t=0150007000000000\&ag=00 (consultado enero de 2019).

IPPC. 2019. Glossary of phytosanitary terms (as adopted by CPM14). International Standards for Phytosanitary Measures (ISPMs) 5-International Plant Protection Convention-Food and Agriculture of the United Nations (FAO). https://www.ippc. int/en/publications/622/ (consultado febrero de 2019). 
Janse, J. D. y A. Obradovic. 2010. Xylella fastidiosa: its biology, diagnosis, control and risks. Journal of Plant Pathology 92(1): 35-48.

Júarez-Jaimes, V., L. Alvarado-Cárdenas y J. L. Villaseñor. 2008. Apocináceas y Asclepiadáceas (Dicotiledóneas). Catálogo taxonómico de especies de México. In: Ocegueda, S. y J. Llorente-Bousquets (coords.). Capital Natural de México, Conocimiento actual de la biodiversidad. vol. I: CD1. Comisión Nacional para el Conocimiento y Uso de la Biodiversidad. México, D.F., México.

Lira-Noriega, A., J. Soberón y J. Equihua. 2018. Potential invasion of exotic ambrosia beetles Xyleborus glabratus and Euwallacea sp. in Mexico: a major threat for native and cultivated forest ecosystems. Scientific Reports 8: 10179. DOI: https://doi.org/10.1038/s41598-018-28517-4

Luck, J., R. Mann, B. van Rijswujk, J. Moran y P. Merriman. 2010. National Diagnostic Protocol for Pierce's Disease, Xylella fastidiosa, protocol number NDP6, endorsed 18 February 2010. http://www.fredon-corse.com/standalone/6/9F69m7rkDKuwbxV9Mu9DnL6a.pdf (consultado febrero de 2019).

Parthasarathy, U., K. V. Saji, K. Jayarajan y V. A. Parthasarathy. 2006. Biodiversity of Piper in South India - application of GIS and cluster analysis. Current Science 91(5): 652-658.

Redak, R. A., A. H. Purcell, J. R. Lopes, M. J. Blua, R. F. Mizell y P. C. Andersen. 2004. The biology of xylem fluid-feeding insect vectors of Xylella fastidiosa and their relation to disease epidemiology. Annual Review Entomology (49): 243-270. DOI: https://doi.org/10.1146/annurev.ento.49.061802.123403

Rocha, J. G., F. Zambolim, F. X. Vale, E. M. Zambolim, A. Bergamin Filho, W. C. Jesus Júnior y B. Hau. 2006. Quantificação dos danos causados por Xylella fastidiosa em cafeeiro. Summa Phytophatologica (32 S): 90-91.

Rzedowski, G. C. y J. Rzedowski. 2004. Manual de malezas de la región de Salvatierra, Guanajuato. Flora del Bajío y Regiones Adyacentes, fascículo complementario XX: 1-315.

Scheldeman, X., L. Willemen, G. Coppens d'Eeckenbrugge, E. Romeijn-Peeters, M. T. Restrepo, J. Romero Motoche, D. Jiménez, M. Lobo, C. I. Medina, C. Reyes, D. Rodríguez, J. A. Ocampo, P. Van Damme y P. Goetghebeur. 2007. Distribution, diversity and environmental adaptation of highland papayas (Vasconcellea spp.) in tropical and subtropical America. Biodiversity and Conservation 16(6): 1867-1884. DOI: https://doi.org/10.1007/978-1-4020-6444-9_19
SENASICA. 2017. Enfermedad de Pierce, Campañas y Programas Fitosanitarios. Servicio Nacional de Sanidad, Inocuidad y Calidad Agroalimentaria (SENASICA). Cd. Mx., México. http://www.senasica.gob.mx/?id=4521 (consultado marzo de 2017).

SENASICA. 2018. Estrategia operativa de la campaña contra Enfermedad de Pierce (Xylella fastidiosa subsp. fastidiosa). Servicio Nacional de Sanidad, Inocuidad y Calidad Agroalimentaria (SENASICA). Cd. Mx., México. https://www.gob. $\mathrm{mx} / \mathrm{cms} /$ uploads/attachment/file/283579/Estrategia_operativa_2018_Pierce.pdf (consultado junio de 2019).

SENASICA. 2019. Enfermedad de Pierce (Xylella fastidiosa subsp. fastidiosa). Servicio Nacional de Sanidad, Inocuidad y Calidad Agroalimentaria (SENASICA). Ficha Técnica 26: 1-14.

Servín-Villegas, R., A. Tejas-Romero, V. Lebsky, C. Palacios-Cardiel, R. Dominguez-Cadena y M. Dominguez-León. 2009. Hospederos de Homalodisca liturata (Homoptera: Cicadellidae), en Baja Balifornia Sur, México; una chicharrita transmisora de patógenos. Centro de Investigaciones Biológicas Del Noroeste (CIBNOR). La Paz, México. http://www.socmexent. org/entomologia/revista/2009/EF/735-739.pdf (consultado junio de 2018).

SIAP. 2019. Cierre de la producción agrícola. Servicio de Información Agroalimentaria y Pesquera (SIAP), Gobierno de México. Cd. Mx., México. http://nube.siap.gob.mx/cierreagricola/ (consultado enero de 2019).

Sisterson, M. S., C. A. Ledbetter, J. Chen, B. S. Higbee, R. L. Groves y K. M. Daane. 2012. Management of almond leaf scorch disease: long-term data on yield, tree vitality, and disease progress. Plant Disease 96(7): 1037-1044. DOI: https://doi. org/10.1094/PDIS-08-11-0693-RE

SNIB. 2019. Sistema Nacional de Información sobre Biodiversidad. Comisión Nacional para el Conocimiento y Uso de la Biodiversidad. http://www.snib.mx/

Sosa, V. y I. Loera. 2017. Influence of current climate, historical climate stability and topography on species richness and endemism in Mesoamerican geophyte plants. PeerJ 5: e3932. DOI: https://doi.org/10.7717/peerj.3932

Sun, J., E. Kouranova, X. Cui, R. H. Mach y J. Xu. 2013. Regulation of dopamine presynaptic markers and receptors in the striatum of DJ-1 and Pink1 knockout rats. Neuroscience Letters 557: 123-128. DOI: https://doi.org/10.1016/j. neulet.2013.10.034 
Sunil, N., N. Sivaraj, K. Anitha, B. Abraham, V. Kumar, E. Sudhir, M. Vanaja y K. S. Varaprasad. 2009. Analysis of diversity and distribution of Jatropha curcas L. germplasm using Geographic Information System (DIVA-GIS). Genetic Resources and Crop Evolution 56(1): 115-119. DOI: https://doi. org/10.1007/s10722-008-9350-x

Townsend, P. A. 2003. Predicting the Geography of Species' Invasions via Ecological Niche Modeling. The Quarterly Review of Biology 78(4): 419-433. DOI: https://doi. org/10.1086/378926

Townsend, P. A. y D. A. Vieglais. 2001. Predicting Species Invasions Using Ecological Niche Modeling: New Approaches from Bioinformatics Attack a Pressing Problem: A new approach to ecological niche modeling, based on new tools drawn from biodiversity informatics, is applied to the challenge of predicting potential species' invasions. BioScience 51(5): 363-371. DOI: https://doi. org/10.1641/0006-3568(2001)051[0363:psiuen]2.0.co;2

UCANR. 2019. UC Pest Management Guidelines, Grape, Sharpshooters. University of California Agriculture and Natural Resources (UCANR). UCANR Publication 3448. http://ipm.ucanr. edu/PMG/r302301711.html (consultado julio de 2019).

UNAM. 2019. Portal de Datos Abiertos, Colecciones Universitarias. Universidad Nacional Autónoma de México. Cd. Mx., México. https://datosabiertos.unam.mx (consultado abril de 2019).

Vargas-Ponce, O., R. Ramírez Delgadillo, H. J. Arreola-Nava, M. Cedano Maldonado, R. González Tamayo, L. M. González Villarreal, M. Harker, L. Hérnández-López, R. E. Martínez González, J. A. Pérez de la Rosa. 2017. Las plantas con flores (Angiospermas). In: CONABIO y SEMADET (eds.). La bio- diversidad en Jalisco. Estudio de Estado. Vol. II. Comisión Nacional para el Conocimiento y Uso de la Biodiversidad (CONABIO) y Secretaría de Medio Ambiente y Desarrollo Territorial (SEMADET). Cd. Mx, México. Pp. 123-133.

Vázquez-Yanes, C., A. I. Batis Muñoz, M. I. Alcocer Silva, M. Gual y C. Sánchez. 1999. Árboles y arbustos potencialmente valiosos para la restauración ecológica y la reforestación. Reporte técnico del proyecto J084. Comision Nacional para el Conocimiento y Uso de la Biodiversidad - Instituto de Ecología, Universidad Nacional Autónoma de México. Cd. Mx., México http://www.conabio.gob.mx/conocimiento/ info_especies/arboles/doctos/18-simmo1m.pdf (consultado julio de 2019).

Villaseñor, J. L. y F. J. Espinosa-García. 1998. Catálogo de malezas de México. Universidad Nacional Autónoma de México, Consejo Nacional Consultivo Fitosanitario y Fondo de Cultura Económica. Cd. Mx., México. 449 pp.

Villaseñor, J. L. y F. J. Espinosa-García. 2004. The alien flowering plants of Mexico. Diversity and Distributions. 10 (2): 113-123. DOI: https://doi.org/10.1111/j.1366-9516.2004.00059.x

Vibrans, H. 2009. Malezas de México. Comision Nacional para el Conocimiento y Uso de la Biodiversidad. Cd. Mx., México. http://www.conabio.gob.mx/malezasdemexico/apocynaceae/catharanthus-roseus/fichas/ficha.htm (consultado marzo de 2019).

Vibrans, H. 2012. Malezas de México. Comision Nacional para el Conocimiento y Uso de la Biodiversidad. Cd. Mx., México. http://www.conabio.gob.mx/malezasdemexico/2inicio/home-malezas-mexico.htm (consultado noviembre de 2018). 